\title{
Professoras bem-sucedidas são professoras reflexivas?! \\ a prática da reflexividade nas ações pedagógicas de professoras nos anos iniciais de escolaridade
}

\author{
Are successful teachers \\ reflective teachers?!

Luciana Miyuki Sado UTSUMI*

RESUMO: Este estudo, expresso na modalidade narrativa, consiste numa pesquisa processual, de natureza qualitativa. Tem como pressuposto que o papel do professor implica uma responsabilidade que resulta em exigência de aperfeiçoamento constante. Tal professor corresponde ao profissional que manifesta atitude de reflexão sobre sua prática, não apenas em sua preparação, mas durante o seu desenrolar e depois desta, procurando extrair da própria ação elementos que ajudem a melhorá-la constantemente. Sob tais aspectos, destaco a prática reflexiva de professoras do Ensino Fundamental, nos anos iniciais de escolaridade, relativa a suas ações pedagógicas bem-sucedidas em aulas, que enfoquei como objeto de investigação. A coleta de dados da pesquisa deu-se por meio de entrevistas semi-estruturadas, relatos orais, observação de aulas e notas de campo. A análise dos dados, a discussão dos resultados e os encaminhamentos possíveis para a Formação de Professores foram construídos levando-se em conta critérios da Investigação Narrativa. Das conclusões, destacam-se: a) as professoras realizam práticas reflexivas de tipos e níveis diferentes, contudo, tais reflexões ocorrem visivelmente atreladas aos seus conflitos didático-pedagógicos, cada qual em seu contexto específico de ação; b) as professoras conseguem realizar reflexões na sua ação, bem como reflexões sobre a sua ação com aproximações em relação à literatura pedagógica, ainda que com ausência dos aspectos que conferem maior criticidade à reflexão. Assim, ressalto a importância do progresso da escola em consonância com a profissionalização do trabalho docente, através da consideração de cada contexto específico, num movimento de busca de sentido para o ensino e para a aprendizagem.

\footnotetext{
* Mestre em Educação pela Universidade Metodista de São Paulo - UMESP. Email luciana.sado@estadao.com.br

Olhar de professor, Ponta Grossa, 8(2): 107-123, 2005.
} 
Palavras-chave: professor bem-sucedido, prática reflexiva, professor reflexivo; formação de professores

\begin{abstract}
This study consists of a procedural research through a qualitative approach in narrative format. It assumes the teacher's role as one of much responsibility and one which demands constant improvement. This kind of teacher is engaged in reflecting on the teaching practice, not only in the preparation phase but also during and after it, with the objective of finding elements which can help in constantly improving the process. Bearing this in mind, some aspects are highlighted here: the reflective practice of teachers in primary school, in the initial years of schooling, related to their successful pedagogical actions in class, which are the object of this study. For this study, data was collected by means of semi-structured interviews, oral accounts, lesson observation and field notes. Data analysis, discussion of the results and the eventual follow-up processes for teacherdevelopment were gathered taking into consideration the criteria of the Narrative Investigation. From the conclusion, the following points were highlighted: a) teachers carry out different types and levels of reflective practices; however, such reflections are clearly related to doubts they have in their teaching, each within a specific action context; b) teachers are able to reflect on their actions as well as reflecting about them based on approaches found in specific books even with the absence of a more critical approach. Therefore it is important that the progress of a school happens together with teachers' becoming more professional, taking each specific context into consideration and always searching for an objective in teaching and learning.
\end{abstract}

Key words: successful teacher, reflexive practice, reflexive teacher, teacher training

\section{TECENDO CONSIDERAÇÕES INICIAIS}

Segundo Gadotti (2003), o professor, no presente, precisa ser um profissional capaz de criar conhecimento, seja através da pesquisa de cunho acadêmico, seja por meio da prática reflexiva em seu contexto de trabalho. É preciso reconhecer que o contexto atual coloca novos desafios para a escola, para o ensino, para o profes- sor, para o aluno.

Com relação a essas exigências ditas atuais - do e no trabalho docente, é inevitável que nos perguntemos: mas esses desafios não foram desde sempre necessários à prática educativa?

É preciso, certamente, reconhecer que - justamente por falta de preparo ou de reflexão - as mudanças do paradigma emergente ${ }^{1}$ são enfrentadas pelos professores de forma des-

${ }^{1} \mathrm{O}$ paradigma emergente refere-se aos desafios e demandas educacionais apontados como referenciais do pós-modernismo. 
conexa, confusa, sem relação com o seu cotidiano escolar. E esse sentimento de medo/incapacidade/incompetência, frente às exigências constantes e crescentes, pode ser atribuído à falta de clareza - por parte dos professores afetados - do contexto sócio-histórico que as impulsiona, a partir do qual elas brotam. Nesse sentido, Contreras (2002, p. 156) defende que a reflexão dos docentes favoreceria a análise teórica, posto que uma teoria crítica lhes permitiria perceber qual a situação em que se encontram. Dessa forma, ao aumentar o compromisso do valor que a educação tem para seus alunos, os professores começarão a perguntar-se sobre o sentido do que fazem e a construir seus próprios conhecimentos críticos, mostrando sua capacidade de usar a inteligência para a compreensão e a transformação social. Ou seja, começarão a intelectualizar seu trabalho. De forma semelhante, conceber o trabalho dos professores como trabalho intelectual significa desenvolver 'conhecimento sobre o ensino' de forma tal que se reconheça sua natureza socialmente construída e o modo pelo qual este se relaciona com a ordem social. Além disso, certamente serão reconhecidas as possibilidades transformadoras implícitas no contexto social das aulas e do próprio processo de ensino.
Ser professora faz parte da minha existência, é uma das paixões ${ }^{2}$ que alimentei/alimento em vida. No decorrer da experiência construída no trabalho docente, pude partilhar efetivamente da idéia de que o papel do educador é de uma responsabilidade de aperfeiçoamento constante, de ressignificação da prática pedagógica com vistas a propiciar o aprendizado dos alunos. Partilhei/partilho, igualmente, da idéia de que o professor é sempre $u m$ aprendiz e de que o seu desenvolvimento profissional, uma vez iniciado, torna-se inacabado desde qualquer ponto de vista: filosófico, pedagógico, educativo, político, corporal...

Embora manifeste uma experiência profissional ainda restrita ${ }^{3}$, em meio à vivência da complexidade do trabalho docente em sala de aula, me senti, inúmeras vezes, sozinha para agir com segurança intelectual e emocional, frente a tantos imprevistos, desafios, urgência na tomada de decisões, exigência de adaptação às mudanças impostas, dentre tantos outros fatores que abalaram a lógica e a rigidez do meu conceito de mundo. $\mathrm{O}$ cotidiano escolar tornava-se cada dia mais complexo na minha ação docente, considerando-se que o professor já nasce inserido em seu cotidiano. Parafraseando Cunha (1989), isso quer dizer que, como todo indivíduo, o professor é simultaneamente

\footnotetext{
${ }^{2}$ No sentido usado por Madalena Freire.

${ }^{3}$ Exerci a função de professora de $2^{\mathrm{a}}$ e $3^{\mathrm{a}}$ séries do Ensino Fundamental, durante seis anos consecutivos, em uma mesma instituição escolar.
} 
um ser particular e um ser genérico; que no seu cotidiano ele trabalha com estas duas forças: as que vêm da generalização da sua função e as que partem dele enquanto individualidade. Nem sempre ambas caminham no mesmo sentido. Contudo, muitas vezes, é do conflito entre elas que se origina a mudança das atitudes do professor. Do ponto de vista educativo, os professores certamente sabem que o seu trabalho está mudando, no mesmo ritmo de mudança do contexto no qual o desempenham. À medida que as escolas vão se reestruturando, a qualidade da aprendizagem dos alunos deverá vir acompanhada, de forma inerente e constante, do desenvolvimento da qualidade da profissão do professor, que se pauta quer pelos objetivos pedagógicos quer pelas pressões atuais, com as quais têm que lidar agora. Como conseqüência dessa insegurança e da insistência de uma nova postura diante de sua prática pedagógica, os professores logo percebem como eu - sua ineficácia diante do processo de ensino e de aprendizagem, na medida em que suas dificuldades em coordenar diferentes situações adequadas de ensino transformam-se em dificuldades de assimilar os conhecimentos por parte dos alunos (PONTES, 1995).

A primeira percepção de novas exigências no trabalho docente refere-se à demanda na formação das gerações do presente e do futuro, para um contexto incerto, instável, em movimento acelerado. Nesse contexto, a necessidade de construir uma nova/ outra idéia do trabalho do professor pode ser furto intencional da reflexão criteriosa, como diz Cunha (1989). Mas pode ser, também, apenas algum tipo de resposta às pressões da sociedade e ao aparecimento de situações não previstas. Vale salientar, porém, que estas últimas podem levar à primeira, isto é, a pressão da realidade pode provocar a reflexão.

Como afirma Saviani (2000), todos e cada um de nós nos descobrimos existindo no mundo (existência que é agir, sentir, pensar). Tal existência transcorre de forma espontânea, até que algo interrompe o seu curso, interfere no processo alterando a sua seqüência natural. Aí, o homem é levado, é obrigado mesmo, a se deter e examinar, procurar descobrir o que é esse algo (problema). Ao desafio da realidade, representado pelo problema, o homem toma uma atitude e responde com reflexão ${ }^{4}$.

\footnotetext{
${ }^{4}$ Pude saber que, constantemente, o homem é levado a refletir sobre sua ação e buscar respostas aos desafios propostos e é nesse processo que constrói conhecimento. Por isso se assinala que o conhecimento nasce da ação e é na ação que este se constitui, quando confronta a necessidade permanente de aprender, de produzir ou de adquirir novo conhecimento. Entende-se, pois, ser próprio dos seres humanos agir no mundo, uma vez que todas as pessoas têm conhecimentos e produzem conhecimentos.
}

$\overline{110}$ Olhar de professor, Ponta Grossa, 8(2): 107-123, 2005. 
Tais considerações contribuíram para que eu pudesse compreender que a capacidade de refletir do professor é também afetada pelos constrangimentos da situação (por exemplo, o peso do trabalho ou a pressão para a inovação), pelas limitações pessoais (por exemplo, nível de desenvolvimento ou de conhecimento) e pelo bemestar emocional (por exemplo, autoconfiança, auto-estima, resposta a críticas negativas). Aprendi com o estudo de Serrazina (1998), por exemplo, sobre a importância da reflexão sobre as práticas, pois podemos, como professores, desenvolver novas maneiras de pensar, de compreender, de agir e de equacionar os problemas da nossa prática, adquirindo uma maior conscientização pessoal e profissional sobre o que é ser professor e como ser um professor que, de modo consistente, questiona as suas próprias práticas.

Entendi - nos termos de Oliveira e Serrazina (1998) - que, de modo geral, os(as) professores(as) que refletem em ação e sobre a ação estão envolvidos(as) num processo investigativo, não só tentando compreender-se a si próprios como professores, mas também procurando melhorar o seu ensino. Por isso, podese dizer que a reflexão contribui para a conscientização dos professores, das suas teorias subjetivas, isto é, das teorias pessoais que informam a sua ação. Os professores são, pois, conduzidos - através da reflexão na sua própria prática e, principalmente, através da reflexão sobre ela - a obter uma visão crítica do contexto estrutural ou ideológico em que estão trabalhando.

Para meu próprio governo, pude concluir - evocando Ghedin ${ }^{5}$ - que não obstante o fato de que nós, os professores, nos encontrarmos freqüentemente excluídos da discussão sobre as finalidades do ensino e da educação, precisamos levar em consideração, em nossas reflexões e ações, o contexto em que nos inserimos como sendo condicionante e determinante de nossas próprias práticas pedagógicas. Contudo, me parece inevitável que nós, professores(as), tenhamos clareza de que há necessidade de nos adequarmos, de forma crítico-reflexiva, aos desafios e demandas educacionais apontados como referenciais do pós-modernismo, superando e ultrapassando concepções absolutistas e prejudiciais ao pleno desenvolvimento do processo humano de ensino e de aprendizagem.

Foi sobremaneira importante, no curso de minha trajetória profissional de professora e pesquisadora, compreender que, ao levar em conta a contextualização da educação, urge concentrar esforços no desenvolvi-

${ }^{5}$ Professor-reflexivo: da alienação da técnica à autonomia da crítica. Disponível em: < http://www.anped.org.br/24/tp.htm >.

Olhar de professor, Ponta Grossa, 8(2): 107-123, 2005. $\overline{111}$ 
mento profissional dos professores, como recurso imprescindível ao atendimento das demandas, quer pedagógicas quer sociais, características da sociedade contemporânea da pósmodernidade e da educação para o e do século XXI.

Através de experiências próprias, por mim vivenciadas e acumuladas, assumi que o papel do educador é de uma inegável responsabilidade e de uma exigência de aperfeiçoamento constante, para que possa apresentar-se como uma ação eficiente e eficaz. Contudo, inúmeras vezes nos sentimos sozinhos, isolados e sem instrumentos adequados para realizar, na nossa prática cotidiana de sala de aula, a tarefa de educar, assumindo posições que se fundam em conhecimento atualizado (segurança intelectual) e em tranqüilidade emocional. Assim, passamos a re-fletir sobre formas de redimensionar a nossa prática pedagógica, para aprimorá-la de forma tal que possa contemplar os termos da realidade e o interesse dos alunos, sem, contudo, perder como referência os objetivos de ensino e de aprendizagem numa prática reflexiva, com vistas a uma ação pedagógica bem-sucedida.

Foram circunstâncias de desconforto, como a anteriormente exemplificada, que me fizeram optar pela temática da prática reflexiva para o desenvolvimento da pesquisa em questão, com o intuito de conhecer para compreender o que os professores pensam sobre o seu ensino e como refletem sobre sua prática enquanto ensinam.

Em estudo específico, Pimenta (2002, p. 18-22) explicita que o conceito de professor reflexivo veio à tona nas discussões que se faziam no movimento de valorização da formação e da profissionalização de professores, a partir de 1990, em diferentes países. Diante das apropriações indiscri-minadas, a-críticas, sob a forma de "modismo" de tais idéias, caracterizou-se o que a autora chama de "mercado de conceitos" em suas primeiras críticas, e que se configuram nas seguintes indagações: “(a) Que tipo de reflexão tem sido realizada pelos professores?, (b) As reflexões incorporam um processo de consciência das implicações sociais, econômicas e políticas da atividade de ensinar? e (c) Que condições têm os professores para refletir?"

Considerando o acima exposto, configurei o meu problema de pesquisa em termos das seguintes indagações:

- O professor em exercício tornase reflexivo pela (prática da) consideração de seus conflitos e de suas dificuldades didático-pedagógicas? Que tipo de reflexão o professor é capaz de fazer por si próprio?

- Em que termos há necessidade de interferência externa - ajuda pedagógica de outros - para que o professor possa vir a fazer reflexões-sobrea-sua-ação, bem como reflexões-na$a c ̧ \tilde{a} o$ ?

- Os professores bem sucedidos 
são professores reflexivos? O perfil de professores que têm uma prática bemsucedida em sala de aula corresponde ao perfil de professores reflexivos apontados na literatura?

Em outros termos, o presente estudo teve por objetivo investigar aspectos vários da ação do professor em aula - e na articulação do seu ensino - para estabelecer relações de compreensão no sentido de "descobrir respostas" para indagações que são freqüentemente postas acerca dos saberes e práticas docentes do próprio professor.

\section{MATERIALE MÉTODO: DESCRE- VENDO O PERCURSO TEÓRICO- METODOLÓGICODA PESQUISA}

Meu primeiro critério para a definição do locus desta pesquisa se fundou na busca de realidades diferenciadas que me possibilitassem o estudo de sujeitos igual e supostamente diferenciados, quer nas suas concepções de educação quer nas suas concepções de ensino, em termos mais específicos. Dessa maneira, optei por situar-me em duas realidades, a saber: (a) uma escola pública, de um lado, e (b) uma escola particular, de outro, a fim de aproveitar a suposta diferenciação de contexto e reconhecer a presença de profissionais, também supostamente diferenciados em decorrência da 'natureza da organização escolar' de cada escola.

Outro critério igualmente relevan- te na minha definição quanto às escolas a serem pesquisadas foi proximidade e acessibilidade do local, de modo a facilitar o meu trânsito entre elas e, em função disso, aproveitar ao máximo o tempo disponível para as interações em campo. Outros aspectos também foram levados em conta por mim, tais como: a) o conhecimento da linha pedagógica da escola; b) o perfil de sua clientela; c) o panorama histórico-cultural da escola; d) as indicações e referências das escolas feitas por professoras por mim conhecidas, meus pares e amigas de trabalho na instituição onde construí minha primeira experiência profissional.

Para a definição dos meus sujeitos da pesquisa, tomei certos cuidados ao usar critérios já considerados para apoiar a seguinte solicitação: que a direção e os pares, bem como professores e professoras - do Ensino Fundamental de $1^{\mathrm{a}}$ à $4^{\mathrm{a}}$ série - indicassem três professores(as) bemsucedidos(as) em relação à problemática da pesquisa inicialmente apresentada. $\mathrm{O}$ critério do número de professores(as) - três - a serem indicados(as) em cada escola foi definido em vista da intencionalidade em: a) configurar tendências de professores(as) bem-sucedidos(as) quer na escola pública, quer na escola particular; b) estabelecer, por sua vez, uma relação paritária (três professores/as em cada escola); c) possibilitar a configuração de tendências, de ambas as escolas, em níveis de aprofundamento 
qualitativamente desejáveis. Segundo Lüdke ${ }^{6}$, uma pesquisa de natureza qualitativa deve contemplar uma amostra indicativa do tema de investigação, ao contrário de uma amostra representativa em números, como se contempla na pesquisa de natureza quantitativa. Assim, a presente pesquisa pautou-se na escolha de professoras consideradas bem-sucedidas, em consonância com a problemática de investigação, de modo a ilustrar, igualmente, a temática da pesquisa.

Era uma tarefa complexa, em vista, principalmente, das variadas concepções de 'professor bem-sucedido' que a literatura apresenta e que cada escola constrói, de acordo com suas representações e seu contexto específico. Pude verificar, através da pesquisa de $\mathrm{Cunha}^{7}$, que a dispersão de escolhas observadas entre os estudantes sobre a idéia que fazem de ' $b o m$ professor' decorre do fato de que, sendo valorativa, essa idéia depende do referencial e da experiência do sujeito que atribui valor. Assim, para a autora, quando se fala de bom professor, as características e atributos que compõem a idéia de "bom" são frutos do julgamento individual do avaliador. Ela ressalta, também, que a questão valorativa é dimensionada socialmen- te. Nesse sentido, "o conceito de bom professor é valorativo, com referência a um tempo e a um lugar, como tal é também ideológico, isto é, representa a idéia que socialmente é construída sobre o professor". Dessa forma, segundo Cunha (1989, cria-se historicamente um rol de atributos que fazem parte do papel do professor, que são assimilados socialmente, sem muita consciência ou atitude reflexiva sobre eles.

De forma correlativa às considerações valorativa e contextual de bom professor, decidi assumir critérios escolares que a direção e os professores das escolas se baseariam para a definição de "professor bemsucedido" e, conseqüentemente, para a definição das professoras como sujeitos da pesquisa. Isso quer dizer que o critério de bom professor, em nível de discussão acadêmica, não foi (im)posto às escolas, em razão justamente das diferentes concepções construídas e veiculadas historicamente. Portanto, cada escola igualmente constrói representações específicas quer do bom professor, quer de professor bem-sucedido, de acordo com as solicitações e desafios de suas realidades multifacetadas e complexas.

Reforço que todos esses critérios

\footnotetext{
${ }^{6}$ Em Simpósio sobre Pesquisa com o professor, sobre o professor e do professor, no qual apresentou trabalho intitulado "Investigando sobre o professor e a pesquisa" - XXI Encontro Nacional de Didática e Prática de Ensino, PUC-PR, ago./set.2004.

${ }^{7}$ Sobre "O bom professor e sua prática" (1989, p. 53;64), igualmente na temática e no título de sua obra.
}

$\overline{114}$ Olhar de professor, Ponta Grossa, 8(2): 107-123, 2005. 
estavam supostamente relacionados aos contornos de uma prática bemsucedida em nível escolar. Posso dizer, pois, que a definição dos critérios de 'professor bem-sucedido' ficou exclusivamente sob consideração das escolas. Ao apostar nessa proposta, acreditei que o presente trabalho já se diferenciava pelo fato de os sujeitos da pesquisa serem definidos pelos próprios atores sociais envolvidos nas escolas, com base em critérios decididamente e autenticamente escolares. De modo especial, posso afirmar que os critérios considerados foram sendo definidos conforme a configuração de processos pedagógicos no dinamismo de sua ocorrência, como se evidencia e parece próprio à presente pesquisa de natureza processual.

Os critérios utilizados na definição das professoras consideradas bem-sucedidas se pautaram em indícios da prática docente no cotidiano escolar, configurando critérios escolares específicos da realidade de cada escola. Sob este último aspecto, o critério considerado na escola pública foi o da participação voluntária por parte das professoras, configurandose como "critério democrático" na definição dos sujeitos da pesquisa.

Sob outra perspectiva, a escola particular considerou como critérios para a definição das professoras aqueles ditos escolares, com base em indícios da prática docente no/do seu cotidiano escolar. Dessa maneira, quando a direção pedagógica enun- ciou (1) o tempo de casa, estava privilegiando as professoras que trabalham há mais tempo na instituição escolar, uma vez que pressupõe que o tempo (maior) de experiência em sala de aula possibilita ao professor uma prática bem-sucedida. Da mesma forma, quando apontou como importante (2) o tempo de atuação na mesma série do Ensino Fundamental de $1^{a} a ̀$ $4^{a}$ série, a direção estava considerando que o professor que atua há mais tempo, numa mesma série, tem maiores condições de antecipar as dificuldades e os desafios de ensino e de aprendizagem específicos de dada faixa etária ou dado nível escolar, sendo, assim, capaz de enfrentar tais especificidades da série com maiores possibilidades de ações pedagógicas bem-sucedidas. Por fim, ao considerar como critério relevante também as (3) ações consideradas bem-sucedidas, passiveis e merecedoras de rememoração ao longo da experiência docente das professoras indicadas, a direção escolar evidenciou que realiza uma avaliação periódica de seu corpo docente, reconhecendo o valor - para a escola - das práticas diferenciadas de suas professoras.

Além desses critérios escolares, pude me valer igualmente das manifestações das professoras nas entrevistas, dos relatos e das observações de suas aulas, bem como das minhas notas de campo, os quais - imbricados quando das análises - possibilitaram a emergência de outros critéri- 
os que qualificaram as professoras sujeitos da pesquisa como sendo, decididamente, professoras bem-sucedidas.

A coleta de dados da presente pesquisa realizou-se pelo uso que fiz de alguns instrumentos, quais sejam:

a) entrevista semi-estruturada ou não-diretiva, isto é, um tipo de entrevista na qual o(a) entrevistado(a) manifesta seu ponto de vista sobre as questões propostas, mantendo a possibilidade de interação, prevalecendo uma atmosfera de influência recíproca entre o pesquisador que pergunta e o sujeito que responde;

b) relato oral, distinguindo-o, no sentido de $\mathrm{Elbaz}^{8}$, como 'um dispositivo metodológico', mas também como uma 'metodologia em si' para articular a narrativa com estudos de Educação;

c) observação de aulas e em aulas, com o propósito de obter dados úteis para alguma relação que se fizesse necessário compreender e esclarecer quando da análise dos dados;

d) notas de campo, como recurso necessário para explicitar relações implícitas no e do cotidiano escolar.

Nesse sentido, tive o propósito de coletar dados descritivos, ou seja, de dados que envolvessem descrições de pessoas, de acontecimentos, de situações, desde as transcrições de entrevistas e de citações para subsidiar uma afirmação ou esclarecer um ponto de vista.

A escolha do método se faz em função do tipo de problema estudado na investigação delineada, de modo que, nos termos de Demo (2002, p. 24), "o método coloca em discussão concepções de ciência". Contudo, "método é instrumento, caminho, procedimento e, por isso, nunca vem antes da concepção de realidade". Assim sendo, entendo que a escolha do método acontece em interação contínua. A interação, a meu ver, é mais profícua quando se dá entre os dados reais (coletados) e as suas possíveis explicações teóricas (estruturação de um quadro teórico para a interpretação e compreensão do fenômeno), através das quais o pesquisador confronta evidências positivas e negativas com as teorias já existentes, e assim vai desenvolvendo a sua teoria.

Aragão (2003) assume a investigação de processos e ações pedagógicas de ensino e de aprendizagem ao propiciar acesso à epistemologia $d a$ investigação narrativa, compreendendo-a no âmbito da história oral de ações educativas escolares. É essa modalidade investigativa que privilegio neste trabalho. Na perspectiva da história oral da educação/ensino do presente, centramos o olhar sobre o

\footnotetext{
${ }^{8}$ Para Elbaz (1983; 1988 apud ARAGÃO, 2003) uma questão importante diz respeito4 ao relato, ao passo que articula a narrativa com inúmeros estudos de Educação, os quais apresentam ou transmitem os seus dados em forma de relatos.
}

$\overline{116}$ Olhar de professor, Ponta Grossa, 8(2): 107-123, 2005. 
que ocorre em rotinas, eventos, acontecimentos, ocorrências várias, vividas em relação aos 'que-fazeres' escolares percebidos e expressos por aqueles que vivem na escola, participando de aulas ou tendo relações com elas. Além disso, assumo os objetivos de investigação que busquei realizar, com o intuito de contribuir para aprimorar o que vem sendo ou tem sido feito de pedagogicamente positivo na escola, pela compreensão daquilo que se faz em termos de processos pedagógicos/educativos, que se tornam acessíveis a partir de narrativas e de relatos investigativos daqueles que os deflagram e constroem quotidiana e dinamicamente no presente. Assim sendo, facilita um tipo de mediação pedagógica significativa que deflagra a construção de conhecimentos dos envolvidos e apreende a visão pessoal dos participantes - significados, maneira com que as pessoas se vêem a si mesmas, suas experiências e o mundo que as cerca. Isso certamente ocorreu no caso presente, em relação a mim (pesquisadora) e às Professoras ${ }^{9}$ (meus sujeitos de pesquisa).

Assumo, ao final, com McEwan e Egan (1995, p. 20), que o uso de narrativas deve ser considerado um meio de também capacitar os professores a refletir sobre sua própria prática, para ampliá-la e ao mesmo tempo enriquecê-la. É, sobremaneira, rica a gama de possibilidades que as narrativas têm aberto para o estudo do ensino, bem como diretas as implicações que essa modalidade de investigação tem para a prática de ensino. O tema da narrativa no ensino e na aprendizagem tem atualmente grande importância para a investigação educativa em todo o mundo, haja vista que a narrativa nos ajuda a compreender o ensino, a vislumbrar novas vias de investigação e a elaborar novos métodos e estratégias de aprimoramento da prática docente de ensino e de aprendizagem.

\section{RESULTADOS: DA DEFINIÇÃO DOS INDICADORES TEMÁTICOS ÀANÁLISE DOS DADOS}

A análise dos dados implicou a organização de todo material obtido durante o desenvolvimento da pesquisa, ou seja, as transcrições de entrevistas e de relatos que expressam as manifestações das professoras participantes. Além disso, levei em conta as notas de campo referentes às minhas observações das aulas $\mathrm{e}$ aos registros das reuniões de $\mathrm{HTPC}^{10}$ da escola pública, os quais serviram como 'pano de fundo' na análise dos dados, buscando relações entre as

\footnotetext{
${ }^{9}$ Quando se faz referência às professoras que participaram da pesquisa, a palavra Professoras é grafada com inicial maiúscula. Já na referência aos professores em geral, foi mantida a grafia com inicial em maiúscula (professores/professoras).

${ }^{10}$ Horário de trabalho pedagógico coletivo.
} 
tendências e padrões - emergentes do material-em níveis mais elevados de abstração, em um tipo de triangulação metodológica. Desse modo, tive a intenção de privilegiar as entrevistas e relatos como deflagradores dos dados para a análise, utilizando das observações de aulas e das notas de campo apenas os aspectos que viessem ao encontro das manifestações das Professoras.

De outra forma, posso dizer que a minha análise dos dados coletados foi baseada em princípios teóricometodológicos e epistemológicos subjacentes à investigação narrativa, tendo em vista, em um primeiro momento, a identificação das concepções subjacentes das Professoras como indicadores de análise e, subseqüentemente, a minha meta-narrativa organizada em função de referências temáticas. Meu propósito foi o de estabelecer relações compreensivas entre os pensamentos diferenciados das Professoras - expressos em seus relatos, captados através das entrevistas e por mim reconstruídos numa tessitura investigativa. Além disso, minha análise incidiu sobre as tendências das Professoras, como aproximações - ou distanciamento de proposições teóricas presentes em teorias veiculadas na literatura específica da educação na atualidade.

Assim, da análise de conteúdo das manifestações de meus sujeitos de pesquisa - entrevistas e relatos emergiram alguns indicadores temáticos ou ideacionais tomados como núcleos de significação, ao serem relacionados com proposições teóricas e temáticas presentes na literatura educacional ou pedagógica. Por isso, com base na problemática de investigação posta, dentre os aspectos emergentes, privilegiei os seguintes:

\section{1) O significado do ensino e da apren- dizagem que as próprias professoras desenvolvem: o que é ensinar e o que é aprender no curso da sua ação pe- dagógica}

Em função dos relatos das Professoras, posso destacar que:

a) As Professoras contempladas na análise em questão apresentam concepções de ensino e de aprendizagem norteadas e caracterizadas por proposições e aspectos pedagógicoeducativos.

b) A qualidade educativa das concepções de ensino e de aprendizagem das Professoras confere aspectos decididamente qualitativos às suas práticas pedagógicas, diferenciadas pela presença do componente da reflexão, ainda que se ponham, quer em âmbito individual, atrelado às dificuldades e conflitos didático-pedagógicos, quer como ações pedagógicas bem-sucedidas.

c) As Professoras manifestam desejo de re-novação e anseiam por diferentes e novas concepções de ensino e de aprendizagem, de forma a garantir seu aperfeiçoamento profissional, mas ressalvando os limites e as possibilidades de cada uma delas. 
2) Tipos de reflexão das Professoras: reflexão-na-ação, reflexão-sobre-aação e reflexão-sobre-a-reflexão-naação, na perspectiva da prática

Em função das análises dos relatos das Professoras, posso destacar o seguinte:

a) As Professoras realizam práticas reflexivas de tipos e níveis diferentes; contudo, tais reflexões ocorrem visivelmente atreladas às suas dificuldades e aos seus conflitos didático-pedagógicos, cada qual em seu contexto específico de ação. Sendo assim, as Professoras manifestam atitude de reflexão quando deu;

· o(a) seu (sua) aluno(a) não apren-

- a prática de ensino da professora não atingiu os objetivos de ensino e de aprendizagem;

- a professora quer aperfeiçoar sua prática docente;

- na prática da professora surgem questões "problemáticas" como a indisciplina, a falta de materiais e de recursos para a realização de uma dada atividade;

- há conflito entre os ideais educativos internos das professoras e as pressões educacionais externas;

- há vários outros momentos de reflexão.

b) As Professoras conseguem realizar reflexões-na-sua-ação, bem como reflexões-sobre-a-sua-ação com aproximações à literatura pedagógica, ainda que com ausência de explicitação de aspectos sociológicos, filo- sóficos, políticos, antropológicos, epistemológicos. Enfim, dos aspectos que conferem maior criticidade e critério à reflexão, ou seja, à reflexividade - qualidade política - dos processos e dos profissionais da Educação. No entanto, a ausência à qual me refiro é relativa à necessidade de explicitação desses aspectos por parte das próprias Professoras, seja por elas não terem ainda consciência de que tais aspectos permeiam suas práticas, seja por não terem também a oportunidade de pensar sobre a qualidade políti$\mathrm{ca}$ - propriamente adjetivada-de sua atividade docente.

c) Penso que o tipo de reflexão que as Professoras conseguem realizar sozinhas limita-se aos aspectos imediatos de suas práticas em sala de aula, visto que, na maioria dos sistemas escolares, como assinala Cunha (1989, p. 66), "os professores vivem num ambiente complexo onde participam de múltiplas interações sociais no seu dia-a-dia. São eles também frutos da realidade cotidiana das escolas, muitas vezes incapazes de fornecer uma visão crítica aos alunos, porque eles mesmos não a têm, porque se debatem no espaço de ajustar seu papel à realidade imediata da escola, perdendo a dimensão social mais ampla da sociedade". Sob outro ângulo de compreensão, entendo que a reflexão das Professoras contempladas na pesquisa encontra-se estreitamente associada à garantia da aprendizagem dos seus alunos, como não poderia deixar de ser, em se tratando da tarefa 
educativa que cada qual assume, decididamente, em termos profissionais: "o professor profissional é, antes de tudo, um profissional da articulação do processo de ensino-aprendizagem em uma determinada situação, um profissional da interação das significações partilhadas"(ALTET, 2001,p. 26).

3) Relato de experiências e práticas diferenciadas das Professoras: suas ações pedagógicas significativas e bem-sucedidas

$\mathrm{Na}$ análise em questão, com base nas manifestações das Professoras, pude verificar que:

a) As Professoras se esforçam por realizar uma prática reflexiva atinente às suas necessidades específicas, partindo de seus conflitos e dificuldades didático-pedagógicos, mas conferindo às suas práticas educativo-pedagógicas a tônica fundamental de uma prática social concreta.

b) A consideração dos estudos educacionais de cunho acadêmico é secundária para as Professoras, frente aos desafios imediatos que elas próprias e suas escolas precisam enfrentar.

c) Cada uma das Professoras - de acordo com a complexidade de seu contexto de atuação - manifestou atitude de reflexão com vistas a uma ação pedagógica diferenciada e bem-sucedida.

d) As Professoras mobilizam competências, técnicas, habilidades, conhecimentos, saberes, estratégias, enfim, todo um repertório de "que-fazeres" em suas ações docentes com vistas a conjurar o fracasso escolar.

e) Há grande esforço para a formação de profissionais reflexivos em alguns espaços coletivos de discussão em reuniões escolares, ainda que as temáticas discutidas se limitem aos aspectos imediatos e práticos da sala de aula, confirmando a importância quer da ajuda pedagógica externa, quer do progresso da escola em consonância com o progresso e profissionalização do trabalho docente.

\section{DISCUSSÃO: CONSTRUINDO CONHECIMENTODEAUTORIA}

A par das manifestações analíticas enunciadas, há de se considerar a relevância do exercício da reflexão pelas Professoras em questão, uma vez que suas reflexões são mobilizadas em prol do sucesso do processo de ensino e de aprendizagem e, portanto, têm uma qualidade inegavelmente humana e social. Em termos correlatos, partindo de seus conflitos e dificuldades didático-pedagógicos, as Professoras esforçam-se por realizar uma prática reflexiva atinente às suas necessidades específicas, conferindo às suas práticas educativopedagógicas a tônica fundamental de uma prática social concreta. Portanto, imprimindo às suas reflexões uma qualidade política assumidamente de cunho pedagógico.

A meu ver, se os professores assumirem a responsabilidade pelo su- 
cesso do aluno com consciência teórico-crítica e postura política, a favor de uma ressignificação constante de seu papel, acredito que estaremos caminhando - a saltos qualitativos! em direção a uma real profissionalização da função docente. Contudo, tenho conhecimento de que o sucesso no ensino e na aprendizagem passa por uma série de fatores difíceis de identificar com precisão, dada a condição humana inerente à vida e à profissão de professor.

Na minha compreensão, há um esforço muito grande na formação de profissionais reflexivos num espaço coletivo de discussão - como pude constatar nas reuniões da escola pública - ainda que as temáticas discutidas limitem-se aos aspectos imediatos e práticos da sala de aula. Nesse contexto, corroboro com a idéia de que é preciso desenvolver uma consciência crítica nos futuros professores, seja na formação inicial seja na formação contínua. Quer dizer, é preciso criar; contudo, é mais importante possibilitar espaços de discussão de fundamentos filosóficos/sociológicos/psicológicos/antropológicos/outros, para alicerçar a formação integral dos professores. Sem essa base, as ações correm o risco de ser ingênuas e prejudiciais aos alunos e à formação do sujeito.

Ressalto a importância da inserção de um profissional na escola para fazer a mediação entre as teorias acadêmicas e as práticas dos professores em exercício, e reforço tal propos- ta, no sentido mesmo de capacitar os professores a se tornarem profissionais mais críticos e genuinamente reflexivos.

Acredito que cada uma das Professoras - de acordo com a complexidade de seu contexto de atuação manifestou atitude de reflexão com vistas a uma ação pedagógica diferenciada e competente e, portanto, bem-sucedida. Diante disso, posso dizer que elas são, decididamente, professoras bem-sucedidas!

Pude verificar algumas características relevantes das Professoras sujeitos da pesquisa que se aproximam, em seus vários aspectos, ao perfil de professores reflexivos apontados na literatura. Por outro lado, como já apontei, não há uma consideração explícita, fortalecida, consciente; enfím, não há o reconhecimento da importância de uma reflexão mais crítica por parte das Professoras. Em suas manifestações, deixa de haver a explicitação de elementos que evidenciem aspectos históricos, filosóficos, sociológicos, antropológicos, epistemológicos e políticos.

\section{CONCLUSÕES: PROJETANDO ENCAMINHAMENTOS PARA A FORMAÇÃO DE PROFESSORES}

Em decorrência dessa investigação, tenho indícios de que o perfil das Professoras tomadas como sujeitos desta pesquisa - como professoras tidas como bem-sucedidas - aproxima-se do perfil ou modelo de professor reflexivo 
manifesto na literatura da Educação, pelo menos em alguns aspectos. Contudo, há convergências com 'arestas a serem acertadas', com aspectos a serem criteriosamente adequados.

Acredito que a escola tem de ser organizada de modo a criar condições para a prática reflexiva individual e coletiva, posto que, do mesmo modo como seus professores precisam ser reflexivos, ela também tem de se tornar uma escola reflexiva. Há, em âmbito escolar, necessidade de espaços de liberdade e responsabilidade que favoreçam a capacidade reflexiva dos professores, em que a expressão e o diálogo assumam um papel relevante para o aperfeiçoamento contínuo dos professores. Assim, tanto para a escola quanto para os professores, a presença da atitude constante de reflexão manterá acesa a importante questão relativa à função que os professores e a escola desempenham na sociedade e ajudará a equacionar e a resolver dilemas e problemas do cotidiano escolar.

Em face de tais evidências, é inevitável perguntar: é possível termos um professor reflexivo ideal nos termos efetivos da escola usual, isto é, que possa situar-se em nível real??? Penso que é expressamente desejável a existência de professores reflexivos (como apontam Schön, Zeichner, Alarcão, dentre outros), bem como professores que se afigurem como intelectuais críticos (como apontam Giroux, Contreras, Pérez-Gómez, dentre outros), que possam atuar em sala de aula e conduzir ou mediar ações pedagógicas relevantes, passíveis de existência em níveis da realidade escolar.

Em decorrência do presente estudo por mim realizado, penso ter condições de apresentar lucubrações à guisa de encaminhamentos, que podem vir a constituir contribuições para a Formação de Professores. As minhas cogitações evidenciam a necessidade e a importância de se pensar sobre:

- a Educação como processo de humanização;

- a construção de um projeto educativo;

- a valorização das práticas dos professores em exercício;

- a articulação entre pesquisadores educacionais e professores em exercício;

· a consideração das competências profissionais mobilizadas por professores em sala de aula;

- a necessidade de interferência externa na e para a formação de professores;

a necessidade de formação profissional integral;

- a articulação entre os saberes da experiência docente e os saberes acadêmicos;

· a dissociação e a distância entre a teoria e a prática;

- o exercício da coerência para efetivação da prática reflexiva e a conquista de autonomia profissional.

Ao final, penso que a pesquisa educacional e a Formação de Educa- 
dores enfrentam o grande desafio de minimizar tal descompasso e buscar cada vez mais aproximações entre o professor reflexivo ideal e o professor bem-sucedido real, ao buscar situar o profissional professor no seu contexto específico, na sua realidade.

\section{REFERÊNCIAS}

ALTET, M. As competências do professor profissional: entre conhecimentos, esquemas de ação e adaptação, saber analisar. In: PAQUAY, L. et al. (Orgs.). Formando professores profissionais: Quais estratégias? Quais competências? Tradução de Fátima Murad e Eunice Gruman. 2. ed. rev. Porto Alegre: Artmed, 2001.

ARAGÃO, R. M. R. Plano de pesquisa: a investigação narrativa no âmbito da história oral de ações escolares de ensino e de aprendizagem em aulas. São Bernardo do Campo, SP: PPGE-UMESP, 2003.

CONTRERAS, J. Contradições e contrariedades: do profissional reflexivo ao intelectual crítico. In: CONTRERAS, J. Autonomia dos professores. Tradução de Sandra Trabucco Valenzuela. São Paulo: Cortez, 2002.

CUNHA, M. I. O bom professor para o aluno de hoje. In: . O bom professor e sua prática. Campinas: Papirus, 1989. (Coleção Magistério: formação e trabalho pedagógico).

Conclusões: da prática à teoria. In: CUNHA, M. I. O bom professor e sua prática. Campinas: Papirus, 1989. (Coleção Magistério: formação e trabalho pedagógico).

DEMO, P. Pesquisar - o que é?. In:
Pesquisa: princípio científico e educativo. 9. ed. São Paulo: Cortez, 2002. (Biblioteca da Educação - Série 1 - Escola, v. 14).

GADOTTI, M. Boniteza de um sonho: ensinar-e-aprender com sentido. São Paulo: Grubhas, 2003.

GHEDIN, E. L. Professor-reflexivo: da alienação da técnica à autonomia da crítica. Disponível em: < http:// www.anped.org.br/24/tp.htm >. Acesso em: 17 out. 2003 .

McEWAN, H.; EGAN, K. Introducción. In: McEWAN, H.; EGAN, K. La narrativa en la enseñanza, el aprendizaje y la investigación. Tradução de Ofelia Castillo. Buenos Aires, Ar: Amorrortu, 1995.

OLIVEIRA, I.; SERRAZINA, L. A reflexão e o professor como investigador. Disponível em: < http:// www.educ.fc.ul.pt/docentes/jponte/fp/ > . Acesso em: 17 out. 2003.

PIMENTA, S. G. Professor reflexivo: construindo uma crítica. In: PIMENTA, S. G.; GHEDIN, E. (Orgs.). Professor reflexivo no Brasil: gênese e crítica de um conceito. São Paulo: Cortez, 2002.

PONTES, E. F. A insatisfação dos professores: conseqüências para a profissionalização. In: (Org.). A causa dos professores. Campinas: Papirus, 1995. (Coleção Magistério: formação e trabalho pedagógico).

SAVIANI, D. A filosofia na formação do educador. In: . Educação: do senso comum à consciência filosófica. 13. ed. Campinas: Autores Associados, 2000. (Coleção Educação Contemporânea).

Encaminhado em: 15/03/05

Aceito em: 06/06/05 